Academic Platform Journal of Engineering and Science

journal homepage: http://apjes.com/

\title{
Zeolit İkameli Geopolimer Betonlarda Kür Şartlarının Etkileri
}

\author{
*1 Ümit Yurt, ${ }^{2}$ Mehmet Emiroğlu \\ ${ }^{1}$ Düzce Üniversitesi, Düzce Meslek Yüksekokulu, İnşaat Bölümü, Düzce/Türkiye, \\ ${ }^{2}$ Düzce Üniversitesi, Teknoloji Fakültesi, İnşaat Mühendisliği Bölümü, Düzce/Türkiye,
}

Araştırma Makalesi

Geliş Tarihi: 12.02 .2020

Kabul Tarihi: 04.05.2020

$\ddot{O} \mathbf{z}$

Küresel ısınmanın zararlı etkileri artarak devam etmektedir. İnşaat sektörünün en önemli yapı malzemelerinden biri olan çimentonun, yüksek enerji tüketen üretim süreci bakımından çevreye olumsuz etkileri olduğu bilinmektedir. Bu zararlı etkilerin azaltılması, çimento üretimi ile doğrudan ilişkilidir. Bu nedenle son yıllarda çimento kullanılmadan üretilebilen çevreci yapı malzemelerine olan ilgi artmıştır. Bu çalışmada, Yüksek Fırın Cürufu (YFC) ile ağırlıkça \%5, \%10 ve \%15 oranlarında zeolit ikame edilerek geopolimer beton karışımları üretilmiştir. Farklı kür şartlarının zeolit içeren geopolimer beton numuneler üzerindeki etkisinin değerlendirilmesi amacıyla üretilen geopolimer beton numuneler 3 farklı kür ortamında $\left(25^{\circ} \mathrm{C}\right.$ hava kürü, $25{ }^{\circ} \mathrm{C}$ su kürü ve $60{ }^{\circ} \mathrm{C}$ su kürü) dayanım kazanmıştır. Kür sonrası sertleşmiş geopolimer beton numuneler üzerinde 3,7 ve 28 gün sonunda basınç dayanımı testleri gerçekleştirilmiştir. Ayrıca, 28 günlük kür süresini takiben yoğunluk ve aşınma deneyleri gerçekleştirilmiştir. Sonuç olarak \%5, \%10 ve \%15 zeolit içeren ve farklı kür şartlarının etkisinin incelendiği geopolimer betonların dayanım ve aşınma özelliklerinin zamana bağlı değişimi karşılaştırmalı olarak değerlendirilmiştir. Genel olarak kür şartlarının değişiminin geopolimer betonların basınç dayanımı ve aşınma dirençlerini etkilediği görülmüştür. En yüksek dayanım değerine $(88 \mathrm{MPa})$ sıcak su kürü $\left(60{ }^{\circ} \mathrm{C}\right)$ uygulanan numuneler ulaşmıştır. Geopolimer beton içerisinde, zeolit kullanım miktarının artmasının aşınma direncine pozitif katkı sağladığını görülmüştür. Sıcak su kürünün $\left(60{ }^{\circ} \mathrm{C}\right)$ aşınma kayıplarını azaltıcı etkisi olduğu gözlemlenmiştir

Anahtar Kelimeler: Aşınma, Basınç dayanımı, Geopolimer beton, Zeolit

\section{The Effects of Curing Condition on Geopolymers Incorporating Zeolit}

\author{
*1 Ümit Yurt, ${ }^{2}$ Mehmet Emiroğlu \\ ${ }^{1}$ Düzce Üniversitesi, umityurt@duzce.edu.tr \\ ${ }^{2}$ Düzce Üniversitesi, mehmetemiroglu@duzce.edu.tr
}

\begin{abstract}
The harmful effects of global warming increasingly continue. Cement, one of the most important building materials of the construction industry, has negative effects on the environment in terms of its production process which consumes high energy. Reducing these harmful effects is directly related to cement production. Therefore, interest in environmentally friendly building materials, which can be produced without cement, has increased in recent years. In this study, geopolymer concrete mixtures were produced by replacing zeolite with blast furnace slag (BFS) at the amount of 5\%,10\% and $15 \%$ (by weight). To evaluate the effect of different curing conditions geopolymer concrete specimens have gained strength with three different curing environments $\left(25^{\circ} \mathrm{C}\right.$ air, $25^{\circ} \mathrm{C}$ water and $60^{\circ} \mathrm{C}$ water curing). Compressive strength tests were carried out at the end of 3,7 and 28 days on the geopolymer concrete samples. Abrasion loss and density tests were carried out at the end of the 28 th-day of curing period. As a result, the change of compressive strength and abrasion loss of geopolymer concretes containing $5 \%, 10 \%$ and $15 \%$ zeolite and the effect of different curing conditions were comparatively. In general, it was seen that compressive strength and abrasion losses of geopolymer concretes were affected by the curing conditions. The specimens cured in $60{ }^{\circ} \mathrm{C}$ water bath reached the highest compressive strength values about $88 \mathrm{MPa}$. The increase in the use of zeolite positively contributes to abrasion resistance in geopolymer concretes. It has been observed that hot water curing application $\left(60{ }^{\circ} \mathrm{C}\right)$ has reduced the abrasion loss.
\end{abstract}

Keywords: Abrasion, Compressive strength, Geopolymer concrete, Zeolite.

${ }^{* 1}$ Sorumlu yazar: Düzce Üniversitesi, İnşaat Bölümü, Düzce/TÜRKIYYE, umityurt@duzce.edu.tr, 050530200 04/ Corresponding author:

Duzce University, Construction Department, Düzce / TURKEY, umityurt@ duzce.edu.tr, 05053020004 


\section{GíRiş}

Günümüzde küresel 1sınmanın zararlı etkileri nedeniyle ortaya çıkan çevresel problemler enerji tüketimi ile doğrudan ilişkilidir. Enerji tüketiminde en büyük role sahip olan çimento üretimi tüm dünyada yaklaşık 4,6 milyar ton üretim kapasitesine ulaşmıştır [1]. Çimento üretiminin toplam maliyeti içerisinde en yüksek payı, enerji maliyetleri (\%20$\% 40$ ) oluşturmaktadır [1,2]. Çimento kullanılarak üretilen kompozit ürünler üretim yöntemleri açısından değerlendirildiğinde yüksek miktarlarda enerji maliyeti oluşturmaktadır [3]. Aynı zamanda çevresel sorunlara neden olmaktadır. $\mathrm{Bu}$ ve benzeri nedenlerle birçok araştırmacı kullanılan çimento miktarını azaltmak için özellikle beton içerisinde İnce Öğütülmüş Yüksek Fırın Cürufu (IÖYFC), Uçucu Kül (UK), Silis Dumanı (SD), atık cam tozu, pirinç kabuğu külü, mermer tozu, zeolit gibi, özellikle puzolonik aktiviteye sahip mineral katkıların beton içerisinde kullanımını incelemişlerdir [4-8]. Bu sayede atık malzemeler bertaraf edilerek aynı zamanda kullanılan çimento miktarı da azaltılmaktadır. Fakat geniş bir kullanım alanına sahip bağlayıcı malzemeler için bu yeterli olmamaktadır. Çimento kullanılarak üretilen yapı malzemelerine alternatif olabilecek ve çimento kullanılmadan üretilebilecek yeni çevreci yap1 malzemelerine olan talep giderek artmaktadir. [9, 10]. Genellikle alkaliler ile aktive edilen alüminosilikatlar, geopolimerler olarak bilinmektedir. Geopolimerler, anorganik en az iki bileşenli bir sistem olarak kabul edilebilir: $\mathrm{SiO}_{2}$ ve $\mathrm{Al}_{2} \mathrm{O}_{3}$ içeriğe sahip reaktif bir katı madde kaynağ1 ve bir veya birden fazla alkalin aktivasyon çözeltisinden oluşmaktadır [11-13]. Özellikle metakaolin, kalsine kaolin, curuf, uçucu kül, silis dumanı, pirinç kabuğu külü, tarımsal atıklar vb. malzemelerin faydalı yeni çevreci ürünlere dönüştürülmesi mümkün olabilmektedir [14, 15]. Geopolimer ürünlerin elde edilebilmesinde alkalilerin yanı sıra 1S1 da gerekmektedir. Özellikle İÖYFC kullanılarak üretilen geopolimer betonların mühendislik özellikleri bakımından iyi sonuçlar verdiği bilinmektedir. Fakat bu özelliklerin geliştirilmesi, ortaya çıkan büzülme sorunlarının giderilmesi, üretilen betonların maliyetinin azaltılması vb. nedenlerle alternatif mineral katkılar kullanılabilir. Çimento kullanılarak üretilen ve farklı özelliklerde mineral katkı içeren betonların kür şartlarının değişimine bağlı olarak incelendiği çalışmalar bulunmaktadır [16, 17]. Fakat çimento kullanılmadan üretilen geopolimer beton, Alkali aktivasyonlu beton ve cüruf beton ile ilgili çalışmalar nispeten daha az sayıda gerçekleşmiştir. Zeolitler, silika ve alümine tetrehedran yapıların oksijen atomunun ortak kullanımı ile üç boyutlu bir görünüme sahip, toprak alkali (Ca) ve alkali ( $\mathrm{Na}$ ve $\mathrm{K}$ ) elementlerinin sulu alümina silikat kristalidir [11, 13]. Zeolitlerin çimento ile birlikte harç ve beton üretiminde kullanılması ile ilgili çeşitli çalışmalar bulunmaktadır [18-24]. Özellikle çimentodan düşük yoğunluğa sahip olması ve özgül yüzeyinin çimentoya göre yüksek olması ve beton içerisinde bulunan boşlukları doldurması vb. özellikleri nedeniyle tercih edilmektedir.

Nikilov, Nugteren ve diğerleri doğal zeoliti yüksek sicaklık uygulayarak metazeolite dönüştürmüş ve geopolimer üretimi için kullanmışlardır. Çalışma kapsamında doğal zeolitin geopolimer malzemeler için kullanım olanağının olduğunu ve $43 \mathrm{MPa}$ basınç dayanımı elde edilebildiğini bildirmişlerdir [9]. Literatür incelendiğinde zeolit'in geopolimer beton içerisinde kullanılması ile ilgili çalışmalar sınırlıdır. $\mathrm{Bu}$ çalışma kapsamında yüksek dayanım ve durabilite özelliklerine sahip zeolit ikameli geopolimer betonların üretimi ve değişen kür koşulları altında beton yaşına bağlı olarak performansı irdelenmiştir. $\mathrm{Bu}$ amaçla farklı kür şartları sonrası 3, 7, 28 günlük dayanım özellikleri ve aşınma dirençlerindeki değişimi karşılaştırmalı olarak incelenmiştir. Gerçekleştirilen bu çalışma ile literatüre zeolit içeren geopolimer beton ile ilgili katkı sağlanarak farklı kür şartlarının geopolimer betonların basınç dayanımı ve aşınma dirençleri üzerindeki etkisi beton yaşının değişimi ile karşılaştırmalı olarak sunulmuştur.

\section{MALZEME VE YÖNTEM}

\subsection{Malzeme}

Çalışma kapsamında kullanılan alkali aktivatörler $(\mathrm{NaOH}$ ve $\mathrm{Na}_{2} \mathrm{SiO}_{3}$ ) Kroma Klor Alkali San. Tic. A:Ş'den temin edilmiş olup, teknik özellikleri Tablo 1'de verilmiştir. Zeolit Rota madencilik A.Ş'den temin edilmiş olup dane çap1 90 mikrondan küçüktür. Ereğli Demir Çelik Fabrikasının bir atığı olan cüruf, Bolu Çimento Fabrikasının Alaplı'da bulunan öğütme tesisinden çimento inceliğinde ögütülmüş olarak temin edilmiştir.

Tablo 1. Alkali aktivatörlere ait kimyasal ve fiziksel özellikler

\begin{tabular}{ccc}
\hline Özellikler & $\begin{array}{c}\text { Sodyum } \\
\text { hidroksit }\end{array}$ & $\begin{array}{c}\text { Sodyum } \\
\text { silikat }\end{array}$ \\
\hline $\begin{array}{c}\text { Molekül Formülü } \\
\text { Molekül Ağırlığ } \\
(\mathrm{g} / \mathrm{mol})\end{array}$ & $\mathrm{NaOH}$ & $\mathrm{Na}_{2} \mathrm{SiO}_{3}$ \\
$\mathrm{Renk}$ & 39,98 & 182.00 \\
$\mathrm{pH}$ & $\mathrm{Beyaz}$ & $\mathrm{Beyaz}$ \\
$\mathrm{Yoğunluk}\left(\mathrm{g} / \mathrm{cm}^{3}\right)$ & $13,18-14,00$ & $11,1-12,59$ \\
$\mathrm{Na}_{2} \mathrm{O}(\%)$ & 2,16 & $1,37-1,45$ \\
$\mathrm{SiO}_{2}(\%)$ & - & 10,46 \\
$\mathrm{H}_{2} \mathrm{O}(\%)$ & - & 27,82 \\
& - & 61,72 \\
\hline
\end{tabular}

Karışımda kullanılan zeolit ve İÖYFC'ye ait kimyasal özellikler Tablo 2'de verilmiştir.

Tablo 2. Mineral katkılara ait kimyasal özellikler

\begin{tabular}{lcc}
\hline Kimyasal Bileșim & İÖYFC & Zeolit \\
\hline $\mathrm{SiO}_{2}$ & 40,49 & 66,75 \\
$\mathrm{CaO}$ & 34,17 & 3,18 \\
$\mathrm{MgO}$ & 7,24 & 1,10 \\
$\mathrm{Al}_{2} \mathrm{O}_{3}$ & 14,56 & 11,3 \\
$\mathrm{Fe}_{2} \mathrm{O}_{3}$ & 1,17 & 1,72 \\
$\mathrm{~K}_{2} \mathrm{O}$ & 1,11 & 3,52 \\
$\mathrm{TiO}_{2}$ & 0,97 & - \\
$\mathrm{Na}_{2} \mathrm{O}$ & 0,61 & 0,43 \\
$\mathrm{SO}_{3}$ & 0,17 & - \\
$\mathrm{K}_{1}$ dirma Kayb1 & - & 12 \\
\hline
\end{tabular}


Tablo 1 ve Tablo 2'de verilen teknik özellikler üretici firmalardan temin edilmiştir. Alkali aktivatörlerden sodyum hidroksit katı olarak temin edilmiş olup laboratuvar ortamında istenilen molarite değerinde $(10 \mathrm{~mol})$ sulu çözelti haline getirilmiştir. Sodyum silikat ise direkt sulu çözelti olarak temin edilip hiçbir işlem yapılmadan kullanılmıştır. Geopolimer beton üretiminde kullanılan ince ve iri agrega kireç taşı kökenli olup maksimum dane çap $16 \mathrm{~mm}$ olarak seçilmiştir.

\subsection{Yöntem}

$\mathrm{Bu}$ çalışmada kapsamında YFC içerisinde doğal zeolit (klinoptilolit) \%5, \%10, \%15 oranlarında kullanılarak çevre dostu geopolimer beton üretimi gerçekleştirilmiştir. Gerçekleştirilen çalışmada kullanılan malzeme miktarları Tablo 3'de verilmiştir.

Tablo 3. Karışım miktarları $\left(1 \mathrm{~m}^{3}\right)$

\begin{tabular}{lc}
\hline Malzemeler & Miktar $\left(\mathrm{kg} / \mathrm{m}^{3}\right)$ \\
$\mathrm{Na}_{2} \mathrm{SiO}_{3}$ (Sulu çözelti) & 158 \\
$\mathrm{NaOH}$ (Sulu çözelti) & 106 \\
İÖYFC & 672 \\
İri agrega & 905 \\
İnce agrega & 607 \\
$\mathrm{Su}$ & 30 \\
\hline
\end{tabular}

Sıcaklık kürünün geopolimerizasyon sürecine katkısı ve kür şartlarındaki değişimin, basınç ve aşınma değerleri üzerindeki etkisi karşılaştırılmalı olarak incelenmiştir. Bu kapsamda üretilen numuneler sıcaklık aktivasyonu için etüv içerisinde 20 saat süren sicaklık aktivasyonu $\left(60{ }^{\circ} \mathrm{C}\right)$ sonrasinda suda $\left(25^{\circ} \mathrm{C}\right)$, havada $\left(25^{\circ} \mathrm{C}\right)$, ve sicak suda $(60$ $\left.{ }^{\circ} \mathrm{C}\right)$ kür etkisi değerlendirilmiştir. Çimento kullanılmadan hazırlanan geopolimer beton karışımlarında, Tablo 3'te verilen oranlara uygun olarak hazırlanan malzemeler (iri agrega, ince agrega, zeolit ve İÖYFC) beton mikserinde ince ve iri agrega beraber karıştırılmasının ardından İÖYFC ve zeolit hareket halindeki miksere aktarılarak kuru olarak iyi bir dağılım elde edilinceye kadar karıştırılmıştır. Karışıma dahil edilecek aktivatörler $\left(\mathrm{NaOH}\right.$ ve $\left.\mathrm{Na}_{2} \mathrm{SiO}_{3}\right)$ birbiri ile karıştırıldıktan sonra mikserde bulunan kuru karışıma yaklaşık 2 dakika içerisinde eklenmiştir. İstenilen dağılımın elde edilmesi takiben daha önceden hazırlanan kalıplara 1 dakika içerisinde vibrasyon uygulanarak 3 aşamada yerleştirilmiştir. Çalışmada kullanılan kalıplar ve böhme aşınma deney cihazı Şekil 1'de görülmektedir. Farklı kür ve karışım değişkenlerine sahip her bir seri için 3 adet numune üretilmiştir. Deneysel çalışma kapsamında üretilen taze geopolimer beton karışımlar, basınç dayanımı deneyi (TS EN 12390-4) için 100x100x100 mm küp kalıplara, sürtünme ile aşınma kaybı deneyi (Böhme) için TS EN 14157'e uygun $71 \mathrm{~mm} \pm 1,5 \mathrm{~mm}$ ölçülerine sahip küp biçiminde deney numune kalıplarına, vibrasyon yardımıyla yerleştirilmiştir $[25,26]$.
Geopolimer beton karışımı mikserden alınarak sarsma tablası üzerindeki kalıplara yerleştirildikten sonra bekletilmeden $60^{\circ} \mathrm{C}$ sabit sicaklığa ayarlanan etüv içerisinde 20 saat boyunca sicaklık kürüne tabi tutulmuştur.

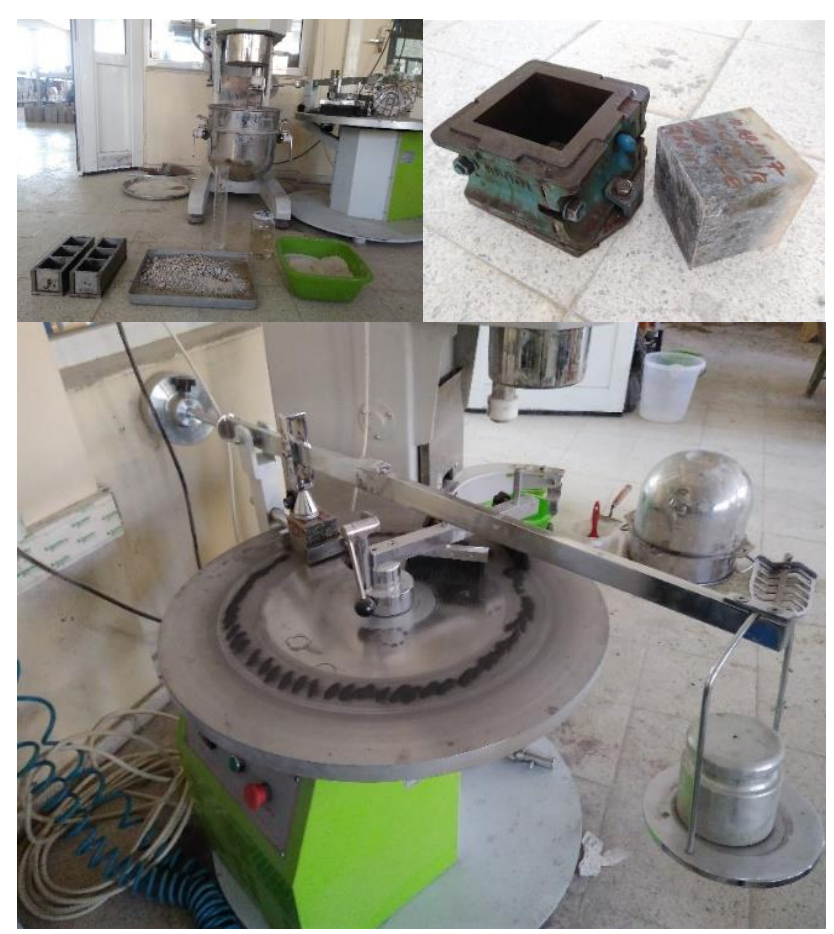

Şekil 1 Böhme aşınma deneyi ve deneysel çalışmada kullanılan kalıp ve malzemeler

Sicaklık aktivasyonu sonrasında farklı günlerde $(3,7,28)$ ve belirlenen sürelerde hava $\left(25^{\circ} \mathrm{C}\right)$, su $\left(25^{\circ} \mathrm{C}\right)$, ve sicak su $\left(60{ }^{\circ} \mathrm{C}\right)$ kürü uygulanmıştır. Farklı kür şartlarında dayanım kazanan numuneler üzerinde fiziksel ve mekanik testler yapılmıştır. Deneysel çalışma kapsamında sürtünme ile aşınma kaybı, basınç dayanımı, yoğunluk gibi fiziksel ve mekanik özelliklerindeki değişim, karşılaştırmalı olarak incelenmiştir. Elde edilen verilerin birbiri ile ilişkisi istatiksel yöntemler kullanılarak incelenmiştir.

\section{DENEYSEL CALISMA VE BULGULAR}

Farklı kür şartlarına ve zeolit ikame oranlarına sahip numunelerin farklı yaşlardaki basınç dayanımı değerlerinin karşılaştırmalı olarak incelendiği grafik Şekil 2'de görülmektedir. Grafik incelendiğinde en yüksek basınç dayanımı değerine (88 MPa) Z5-W60 kodlu numunede ulaşıldığ1 görülmektedir. İlk 3 günlük sonuçlar incelendiğinde zeolit oranının artışı ile dayanım değerleri artmış \%15 zeolit içeriğine sahip numunelerde ise düşüş görülmüştür. Çimento içerisine zeolit ikamesi ile gerçekleştirilen geleneksel beton üretiminde belirli bir ikame oranına (Yaklaşık \%20) kadar kullanıldığında basınç dayanımı değerini arttırdığı bildirilmiştir [20, 22, 23]. Bu yönüyle bu çalışma ile paralellik göstermektedir. Genel olarak sıcak su kürü uygulanan numunelerde beton yaşının artışı ile dayanım özelliklerinde artış görülmüştür. Diğer kür şartlarında genel olarak beton yaşının artışı ile dayanım 
gelişimi arasında doğrusal bir ilişki görülmemiştir. Zeolit ikame oranı \%15 olan numunelerde en yüksek basınç dayanım değeri (81MPa) Z15-W60 kodlu numunede gözlemlenmiştir. Hava küründe dayanım kazanan numunelerin dayanım değerleri diğer kür şartları ile karşılatıldığında daha düşük değerler aldığı belirlenmiştir. Tüm kür şartları genel olarak incelendiğinde (Şekil 2) basınç dayanımı değerleri en yüksek değerden en düşük değere doğru sıralanırsa sıcak su $\left(60^{\circ} \mathrm{C}\right)$, su kürü $\left(25^{\circ} \mathrm{C}\right)$ ve hava kürü $\left(25^{\circ} \mathrm{C}\right)$ olarak elde edildiği görülebilir.

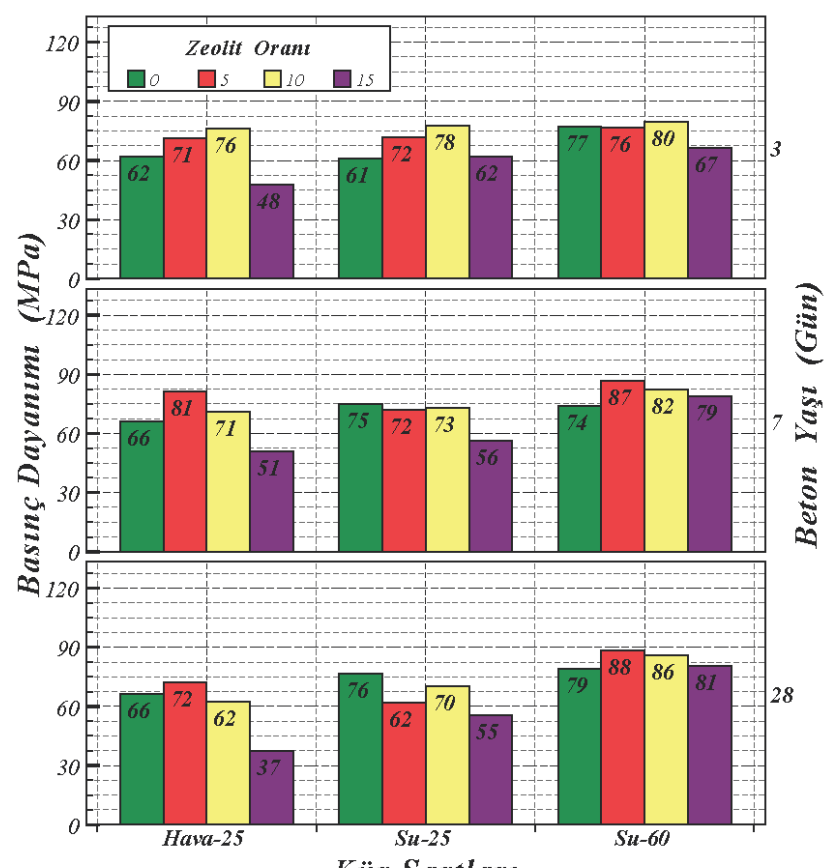

Kür Şartları

Şekil 2. Basınç dayanımı değerleri

Sıcak su kürü uygulanması ile dayanım değerlerinde olumlu bir etki ortaya çıkmıştır. Genel olarak sıcak su kürü uygulanması ile dayanım değerlerinin gelişimi arasında pozitif yönlü bir ilişki olduğu tespit edilmiştir. Sürtünme ile aşınma kayıplarının kür şartlarının değişimine bağlı olarak incelendiği grafikler Şekil 3, 4, ve 5'de görülmektedir.

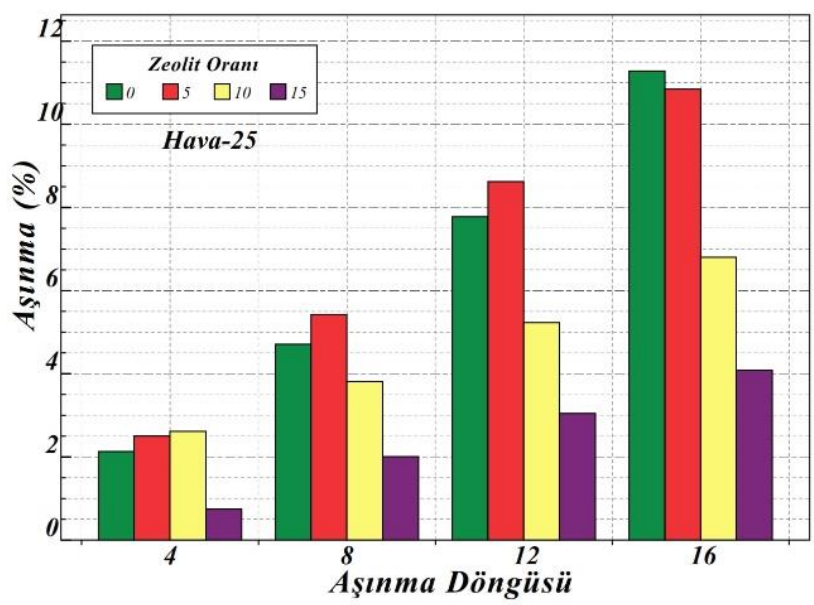

Şekil 3. Hava kürü $\left(25^{\circ} \mathrm{C}\right)$ uygulanan numunelere ait aşınma kayıpları
Sürtünme ile aşınma kayıplarına (Ağırlık kayıpları olarak değerlendirilmiştir) ait grafikler incelendiğinde aşınma döngüsünün artışı ile aşınma kayıpları tüm serilerde doğrusal olarak artış göstermiştir.

Hava küründe dayanım kazanan numunelere ait Şekil 3'de görülen grafik değerlendirildiğinde aşınmaya karşı en iyi direnç gösteren numunelerin $\% 15$ zeolit içeriğine sahip numuneler olduğu görülmüştür. Aşınma döngüsü sonucunda (16 çevrim) en yüksek aşınma kaybı \%100 YFC içeren, en düşük aşınma kaybı ise $\% 15$ zeolit içeren numunelerde görülmüştür. Hava kürü numuneleri için en yüksek ve en düşük aşınma kayıpları sırasıyla \%11,40 ve \%4,12 olarak gerçekleşmiştir.

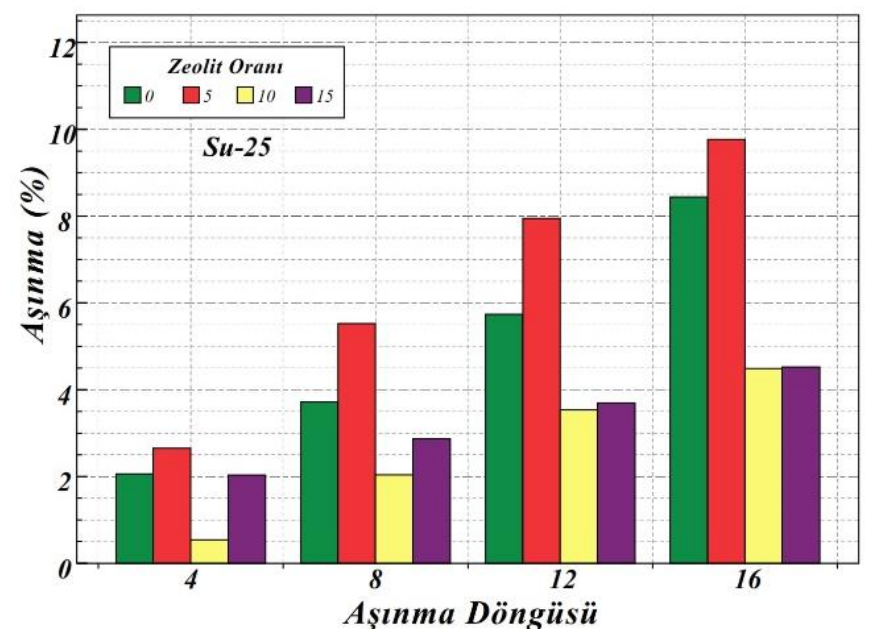

Şekil 4. Su kürü $\left(25^{\circ} \mathrm{C}\right)$ uygulanan numunelere ait aşınma kayıpları

Şekil 4 incelendiğinde en yüksek aşınma kayıpları \%5 zeolit içeriğine sahip serilerden, en düşük aşınma kayıpları ise genel olarak $\% 10$ ve $\% 15$ zeolit içeriğine sahip serilerden elde edilmiştir.

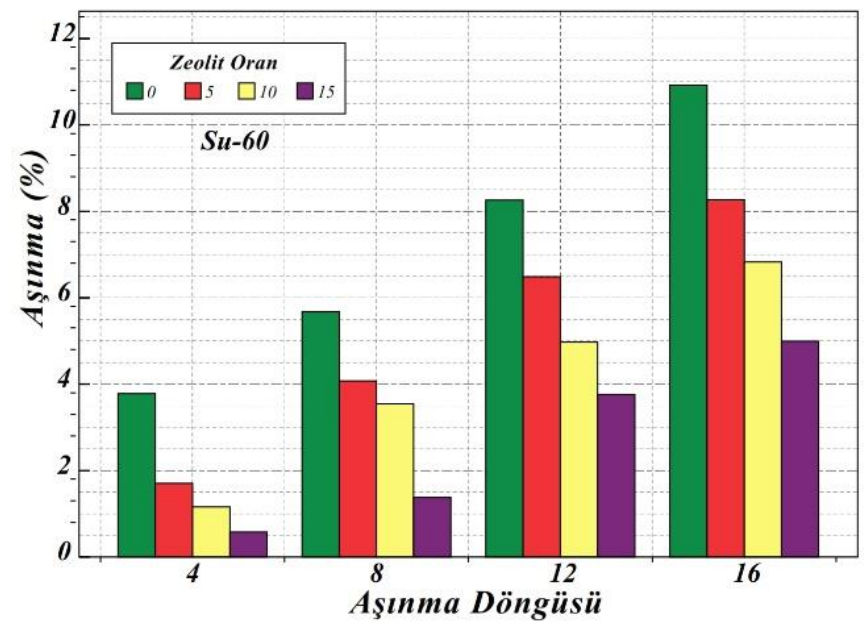

Şekil 5. Su kürü $\left(60^{\circ} \mathrm{C}\right)$ uygulanan numunelere ait aşınma kayılar1

Sicak su kürü uygulanan (Şekil 5) numunelerin zeolit oranın artışı ile aşınma kayıplarını azaldığı görülmüştür. 
Zeolit ikame oranının artışı, sıcak su kürü uygulaması ile birlikte geopolimer betonların aşınma dirençlerine olumlu katkı sağladığı belirlenmiştir. Genel olarak hava küründe dayanım kazanan ve \%100 İÖYFC içeriğine sahip numunelerin aşınma kayıplarının diğer kür şartlarına kıyasla daha yüksek değerler aldığı görülmüştür. Genel olarak aşınma kayıplarının artışı ile aşınma çevrimi arasında doğrusal bir ilişki olduğu görülmektedir. Aşınmaya karşı en yüksek direnç gösteren numunelerde aşınma kayıpları en çok \%11,5 civarında gerçekleşmiştir. Aşınma kayıpları başlangıçta çok küçük değerler almış, aşınma çevriminin artışına bağlı olarak kayıp yüzdeleri artmıştır.

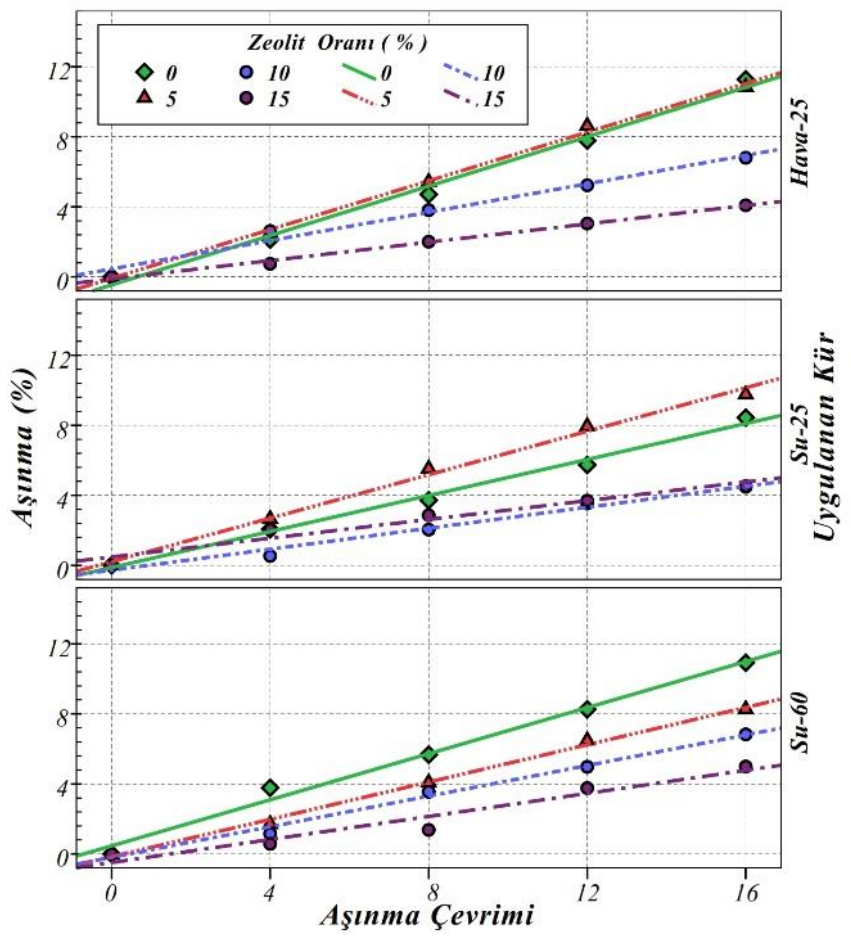

Şekil 6. Regresyon analizi

Farklı kür şartlarında dayanım kazanan ve farklı zeolit ikame oranına sahip geopolimer betonların aşınma döngüsü ve aşınma kaybı arasındaki ilişkiyi belirlemek amacıyla Şekil 6'daki saçılma grafiği oluşturulmuştur. Tüm kür şartlarında dayanım kazanan numuneler zeolit ikame oranının artışına bağlı olarak değerlendirildiğinde, zeolit ikame oranının artışının, aşınmaya karşı dirence olumlu katkı sağladığı görülmüştür. Zeolit içeren geleneksel beton üretiminde zeolit ikame oranının artışı ile aşıma dirençlerinin attığı bildirilmiştir. Özellikle ortam koşullarının aşınma direnci ile birlikte değerlendirilmesi gerektiği ve ikame oranının belirli sınırlar içerisinde kullanıldığı bildirilmiştir [22].

Üretilen numunelerin test sonuçlarının kullanılması ile elde edilen saçılma grafiklerinden (Şekil 6) elde edilen denklemler ve $\mathrm{R}^{2}$ değerleri Tablo 4'de verilmiştir.

Determinasyon katsayısı $\left(\mathrm{R}^{2}\right) \quad 0,90$ değerinden yüksek olduğundan aşınma kayıpları ve aşınma çevrimi arasında güçlü bir ilişki olduğu görülmüştür. Tüm kür şartları ve karışım oranları kendi içerisinde değerlendirildiğinde yüksek oranda pozitif doğrusal determinasyon katsayısı değişim aralığı: $\mathrm{R}^{2}=0,944-0,997$ olarak elde edilmiştir. Tablo 4 değerlendirildiğinde en yüksek ilk üç ilişki sırasıyla Z5-A25, Z5-W60, Z15-A25 kodlu numuneden elde edilmiştir.

Tablo 4 Denklemler ve $\mathrm{R}^{2}$ değerleri

\begin{tabular}{lccc}
\hline $\begin{array}{c}\text { Numune } \\
\text { Kodu }\end{array}$ & $\begin{array}{c}\text { Kür Şartları } \\
\left({ }^{\circ} \mathrm{C}\right)\end{array}$ & Denklem & $\mathbf{R}^{2}$ \\
\hline YFC-A25 & Hava (25) & $\mathrm{Y}=-0,46+0,71 \mathrm{x}$ & 0,991 \\
YFC-W25 & $\mathrm{Su}(25)$ & $\mathrm{Y}=-0,12+0,51 \mathrm{x}$ & 0,993 \\
YFC-W60 & $\mathrm{Su}(60)$ & $\mathrm{Y}=0,46+0,66 \mathrm{x}$ & 0,990 \\
\hline Z5-A25 & Hava (25) & $\mathrm{Y}=-0,08+0,7 \mathrm{x}$ & 0,997 \\
Z5-W25 & $\mathrm{Su}(25)$ & $\mathrm{Y}=0,21+0,62 \mathrm{x}$ & 0,994 \\
Z5-W60 & $\mathrm{Su}(60)$ & $\mathrm{Y}=-0,16+0,53 \mathrm{x}$ & 0,996 \\
\hline Z10-A25 & $\mathrm{Hava}(25)$ & $\mathrm{Y}=0,45+0,26 \mathrm{x}$ & 0,980 \\
Z10-W25 & $\mathrm{Su}(25)$ & $\mathrm{Y}=-0,27+0,3 \mathrm{x}$ & 0,981 \\
Z10-W60 & $\mathrm{Su}(60)$ & $\mathrm{Y}=-0,19+0,44 \mathrm{x}$ & 0,991 \\
\hline Z15-A25 & $\mathrm{Hava}(25)$ & $\mathrm{Y}=-0,12+0,26 \mathrm{x}$ & 0,995 \\
Z15-W25 & $\mathrm{Su}(25)$ & $\mathrm{Y}=0,48+0,27 \mathrm{x}$ & 0,952 \\
Z15-W60 & $\mathrm{Su}(60)$ & $\mathrm{Y}=-0,49+0,33 \mathrm{x}$ & 0,944 \\
\hline
\end{tabular}

Zeolit içeren geopolimer betonların yoğunluk değerleri incelendiğinde geleneksel betona benzer şekilde 2250 $\mathrm{kg} / \mathrm{m}^{3}-2430 \mathrm{~kg} / \mathrm{m}^{3}$ aralığında değişen değerler aldığ görülmüştür. Geopolimer beton üretimi ve sürdürülebilir yap1 malzemelerinin üretilmesi, kullanılması ve yayınlaşabilmesi gerçekleştirilecek çalışmalara bağlıdır. Özellikle üretim sonrası davranışının belirlenmesi kür koşullarına bağlı olarak dayanım ve durabilite özelliklerinin araştırılması gerekmektedir. Bu çalışma kapsamında zeolit ve İÖYC içeren geopolimer betonların ilk aktivasyon sıcaklığı sonrası su kürü uygulanması ile ilerleyen yaşlarda dayanım ve durabilite özelliklerine önemli katkı sağladığ1 kür suyu sıcaklığının artışı ile performansının olumlu etkilendiği görülmüştür. Ancak kür suyu sıcaklığı bu çalışma kapsamında sınırlı bir aralıkta gerçekleştirilmiştir. Sonraki çalışmalarda kür suyu sıcaklığının değişimi ile dayanım ve durabilite özelliklerinin araştırılması literatüre katkı sağlayacaktır.

\section{DEĞERLENDİRME VE SONUÇLAR}

Çalışma sonucunda ulaşılan sonuçlar aşağıda özetlenmiştir.

* En yüksek basınç dayanımı değeri $88 \mathrm{MPa}$ olarak elde edilmiştir. En düşük basınç dayanımı değeri (37 $\mathrm{MPa})$ referans alınarak değerlendirildiğinde kür şartları ve zeolit ikame oranının değişimine bağlı olarak \%137,84 artış gerçekleşmiştir.

*Tüm kür şartları beton yaşına bağlı olarak değerlendirildiğinde en yüksek basınç dayanımı değerleri sıcak su kürü $\left(60^{\circ} \mathrm{C}\right)$ uygulanan numunelerde elde edilmiştir. 
* Sıcak su kürü uygulanan tüm karışımlarda beton yaşının artışı ile dayanım değerlerinde artış görülmüştür. Beton yaşı 3 gün olan numuneler referans alınarak değerlendirildiğinde beton yaşına bağlı olarak en fazla dayanım artışı $(\% 20,9)$ Z15-W60 kodlu numenlerde elde edilmiştir.

* Zeolit ikame oranının artışı aşınma kayıplarının azalmasını sağlamıştır. Zeolit kullanımın aşınmaya karşı dirence olumlu katkı sağladığı gözlemlenmiştir.

Aşınma kayıpları (16 çevrim sonrasında) \%100 İÖYFC içeren numune referans alınarak değerlendirildiğine Hava-25 $\left(25^{\circ} \mathrm{C}\right), \mathrm{Su}-25\left(25^{\circ} \mathrm{C}\right)$ ve $\mathrm{Su}-60\left(60^{\circ} \mathrm{C}\right)$ kodlu numunelerde

Sirasıly \%65,52-\%47,06-\%53,70 oranında düşüş görülmüştür.

*Hava kürü ile dayanım kazanan numunelerde aşınma kayıplarının diğer kür şartlarına kıyasla daha yüksek değerler aldığı belirlenmiştir.

*Aşınma kayıpları başlangıçta çok küçük değerler almış, aşınma çevriminin artışı ile aşınma kayıpları artmıştır.

*Aşınmaya karşı en yüksek direnç gösteren numunelerde aşınma kayıpları maksimum \%11,5 civarında gerçekleşmiştir.

*Tüm karışım oranlarında aşınma kayıpları ve aşınma döngüsü arasında çok güçlü bir ilişski olduğu ve $\mathrm{R}^{2}$ değerlerinin 1'e çok yakın değerler aldığı görülmüştür.

\section{KAYNAKLAR}

[1] G. V. P. Bhagath Singh and K. V. L. Subramaniam, "Production and characterization of low-energy Portland composite cement from post-industrial waste," Journal of Cleaner Production, vol. 239, p. 118024, 2019/12/01/ 2019.

[2] J. Wang, Y. Dai, and L. Gao, "Exergy analyses and parametric optimizations for different cogeneration power plants in cement industry," Applied Energy, vol. 86, no. 6, pp. 941-948, 2009/06/01/ 2009.

[3] W. Zhang, A. Maleki, M. G. Khajeh, Y. Zhang, S. M. Mortazavi, and A. Vasel-Be-Hagh, "A novel framework for integrated energy optimization of a cement plant: An industrial case study," Sustainable Energy Technologies and Assessments, vol. 35, pp. 245-256, 2019/10/01/ 2019.

[4] M. Saribiyik, A. Piskin, and A. Saribiyik, "The effects of waste glass powder usage on polymer concrete properties," Construction and building materials, vol. 47, pp. 840-844, 2013.

[5] S. Subaşı, H. Öztürk, and M. Emiroğlu, "Utilizing of waste ceramic powders as filler material in selfconsolidating concrete," Construction and Building Materials, vol. 149, pp. 567-574, 2017.

[6] A. Subaşı and M. Emiroğlu, "Effect of metakaolin substitution on physical, mechanical and hydration process of White Portland cement," Construction and Building Materials, vol. 95, pp. 257-268, 2015.

[7] Y. Koçak, S. Subaşı, and M. Emiroğlu, "Uçucu külün betonun bazı fiziksel ve mekanik özelliklerine etkisi," Yap1 Teknolojileri Elektronik Dergisi, vol. 7, no. 1, pp. 1427, 2011.

[8] K. Yamanel, U. Durak, S. İlkentapar, İ. İ. Atabey, O. Karahan, and C. D. Atiş, "Influence of waste marble powder as a replacement of cement on the properties of mortar," Revista de la Construcción. Journal of Construction, vol. 18, no. 2, pp. 290-300, 2019.

[9] A. Nikolov, H. Nugteren, and I. Rostovsky, "Optimization of geopolymers based on natural zeolite clinoptilolite by calcination and use of aluminate activators," Construction and Building Materials, vol. 243, p. 118257, 2020/05/20/ 2020.

[10] B. C. McLellan, R. P. Williams, J. Lay, A. van Riessen, and G. D. Corder, "Costs and carbon emissions for geopolymer pastes in comparison to ordinary portland cement," Journal of Cleaner Production, vol. 19, no. 9, pp. 1080-1090, 2011/06/01/ 2011.

[11] P. Rożek, M. Król, and W. Mozgawa, "Geopolymer-zeolite composites: A review," Journal of Cleaner Production, vol. 230, pp. 557-579, 2019/09/01/ 2019.

[12] E. Papa et al., "Zeolite-geopolymer composite materials: Production and characterization," Journal of Cleaner Production, vol. 171, pp. 76-84, 2018/01/10/ 2018.

[13] A. Buchwald, H. D. Zellmann, and C. Kaps, "Condensation of aluminosilicate gels-model system for geopolymer binders," Journal of Non-Crystalline Solids, vol. 357, no. 5, pp. 1376-1382, 2011/03/01/ 2011.

[14] S. Mesgari, A. Akbarnezhad, and J. Z. Xiao, "Recycled geopolymer aggregates as coarse aggregates for Portland cement concrete and geopolymer concrete: Effects on mechanical properties," Construction and Building Materials, vol. 236, p. 117571, 2020/03/10/ 2020.

[15] S. Park and M. Pour-Ghaz, "What is the role of water in the geopolymerization of metakaolin?," Construction and Building Materials, vol. 182, pp. 360-370, 2018/09/10/ 2018.

[16] B. Dündar, İ. İ. Atabey, and Ü. Yurt, "Osmaniye ilinde hazır beton santrallerinde üretilen beton kalitelerinin istatistiksel olarak değerlendirilmesi," 2017.

[17] Ü. Yurt and M. Emiroğlu, "Kendiliğinden Yerleșen Betonların Düşük Sıcaklıklardaki Davranışının Tahribatsız Yöntemlerle İncelenmesi," Akademik Platform Mühendislik ve Fen Bilimleri Dergisi, vol. 6, no. 3, pp. 8-15, 2018.

[18] N. A. Ulloa, H. Baykara, M. H. Cornejo, A. Rigail, C. Paredes, and J. L. Villalba, "Application-oriented mix design optimization and characterization of zeolite-based geopolymer mortars," Construction and Building Materials, vol. 174, pp. 138-149, 2018/06/20/ 2018.

[19] A. Sudagar et al., "A novel study on the influence of cork waste residue on metakaolin-zeolite based geopolymers," Applied Clay Science, vol. 152, pp. 196-210, 2018/02/01/ 2018.

[20] U. K. Sevim and N. Okumuş, "Zeolit ve silika dumanı katkılı betonların mekanik ve geçirimlilik özellikleri," Çukurova Üniversitesi Mühendislik-Mimarlık Fakültesi Dergisi, vol. 26, no. 2, pp. 57-63, 2011.

[21] A. DORUM, A. DORUM, and K. YILDIZ, "Yüksek dayanımlı betonlarda pomza ve zeolitin kullanılabilirliği," Teknik Dergi, vol. 22, no. 106, pp. 53355340, 2011.

[22] K. Yildiz and C. Demirel, "MgSO4 etkisine maruz rijit yol kaplamalarında pomza ve zeolit katkılı betonun 
kullanılabilirliği," Politeknik Dergisi, vol. 17, no. 1, pp. 2329, 2014.

[23] F. Canpolat and K. Y1lmaz, "Doğal zeolit ve uçucu kül katkılı ve katkısız harçların sülfat dayanıklılığı," Eskişehir Osmangazi Üniversitesi Mühendislik ve Mimarlık Fakültesi Dergisi, vol. 15, no. 2, pp. 11-24, 2002.

[24] K. Güçlüer, "Zeolit ve Metakaolinin Gazbeton
Üretiminde Kullanılabilirliğinin Araştırılması," Afyon Kocatepe Üniversitesi Fen Ve Mühendislik Bilimleri Dergisi, vol. 16, no. 2, pp. 338-343, 2016.

[25] "TS EN 12390-4," Beton-Sertleşmiş Beton Deneyleri-Bölüm: 4, TSE Yayınevi, Ankara, Türkiye, 2002. [26] "TS EN 14157," Doğal Taşlar-Aşınma Direncinin Tayini, TSE Yayınevi, Ankara, Türkiye, 2005. 